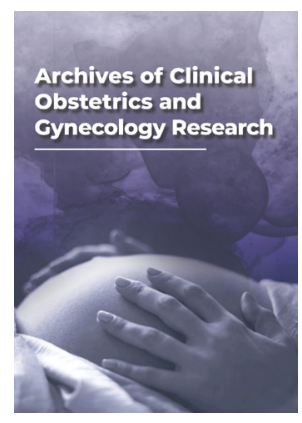

Correspondence

Juliana Yusof

Department of Obstetrics \& Gynaecology, Faculty of Medicine, University Technology of MARA, Sg Buloh, Malaysia

E-mail: drjuliana@uitm.edu.my

- Received Date: 09 Aug 2020;

- Accepted Date: 21 Oct 2020;

- Publication Date: 08 Nov 2020.

Copyright

(c) 2020 Science Excel. This is an openaccess article distributed under the terms of the Creative Commons Attribution 4.0 International license.

\title{
Survivor of maternal dengue shock syndrome with acute fulminant liver failure following liver dialysis
}

\author{
Juliana Yusof* \\ Department of Obstetrics \& Gynaecology, Faculty of Medicine, University Technology of MARA, Sg Buloh, Malaysia
}

\begin{abstract}
This case report describes a pregnant patient who had dengue shock syndrome at 33 weeks gestation. The patient manifested with fever and vomiting and her NS 1 Antigen for dengue was positive. Her platelet dropped dramatically and she went into labour and delivered a fresh still birth baby due to congenital. Her condition deterred after delivery where she became severely jaundice and went into hepatic encephalopathy and liver failure following dengue infection. To prevent maternal mortality , she was electively intubated and liver dialysis was performed of which patient's clinical condition improved dramatically and managed to survive.
\end{abstract}

\section{Case report}

A 33 -year - old Gravida 4 para 3 at 33 weeks gestation with underlying Diabetes Mellitus for 8 years presented with history of fever for two days with vomiting. She lived in dengue endemic area. She was pink, normotensive but febrile with temperature of 38 degrees. Clinically she had mild contraction and clinical palpation revealed uterus at 34 weeks size with cephalic presentation, but it was not engaged. Her cervical os was $3 \mathrm{~cm}$ dilated. Her NS1 Antigen for dengue infection was positive. Baseline platelet was 220 x $10^{9}$ but her liver function test were impaired with aspartate transaminase (AST) level of 413 $\mathrm{U} / \mathrm{L}$, and serum lactate dehydrogenase (LDH) of $445 \mathrm{U} / \mathrm{L}$. She was mildly acidotic with lactate level of $3 \mathrm{mmol} / \mathrm{L}$. Hence she was treated with dengue fever and managed in high dependency ward (HDW). N aceytylcystine (NAC) was given intravenously for her transaminitis. Unfortunately on day 3 of fever, her labour progressed to os $4 \mathrm{~cm}$. Her platelet dropped to $100 \times 10^{\wedge} 9$. She was transfused with 4 units of platelet intrapartum and delivered vaginally to a baby boy 3 hours later. She did not develop postpartum haemorrhage but her baby was born with very poor Apgar Score and intubated at birth. The baby died at day 7 of life secondary to congenital dengue. On day 1 postpartum at day 4 of dengue fever, patient's condition deterred despite she completed the critical phase of dengue for 48 hours. She developed atrial fibrillation, hypotension and warning sign of haemoconcentration which was third space fluid loss with presence of bilateral pleural effusion and ascites. Her platelet dropped to $51 \times 10^{\wedge} 9$, and she went into fulminant liver failure despite on intravenous NAC. Her alanine transaminase (ALT ) raised to $2000 \mathrm{U} / \mathrm{L}$ and $\mathrm{LDH}$ to $5517 \mathrm{U} / \mathrm{L}$. Her acidosis worsened with base excess level of -12.1 and serum lactate of $11 \mathrm{mmol} / \mathrm{L}$. Bedside echo revealed myocardial dysfunction with ejection fraction of $40 \%$. Urgent full blood picture revealed neutrophilia monocytosis with no evidence of haemolysis. She was started on amiodarone for her atrial fibrillation, thiamine for the liver failure and continuos renal replacement therapy (CRRT) for her worsening metabolic acidosis. Unfortunately she developed cardiogenic shock, requiring two inotropes- dobutamine and noradrenaline on day 5 of illness and was electively intubated for hepatic encephalopathy as her ALT abruptly increased to $9000 \mathrm{U} / \mathrm{L}, \mathrm{AST}$ of $4555 \mathrm{U} / \mathrm{L}$ and serum ammonia of $300 \mathrm{mmol} / \mathrm{L}$ on day 6 of illness. Decision of liver dialysis was then made by Intensivist Consultant. Patient had 3 cycles of Molecular Adsorbent Recirculating System (MARS) or liver dialysis also on day 6 of illness of which her lactate, AST, ALT and serum ammonia gradually reduced, to $300 \mathrm{U} / \mathrm{L}, 200 \mathrm{U} / \mathrm{L}$ and $100 \mathrm{U} / \mathrm{L}$ respectively before she was extubated on day 16 of illness. She was on regular physiotherapy under Rehabilitation team in obstetric ward to improve her muscle weakness and was discharged well 2 weeks later (Table 1 and Figure 1).

\section{Discussion}

Pregnancy liver disorder has been associated with $20 \%$ mortality [2]. The main cause of liver failure in pregnancy are Haemolytic Elevated Liver Enzyme and Low Platelet (HELLP syndrome), acute fatty liver [3] and hepatitis E. The first case of MARS in pregnancy was reported in 2008 secondary due to acute fatty liver [4]. This is the first case reported of MARS in pregnancy in relation to dengue shock syndrome (DSS) in our hospital. DSS causing fulminant liver failure has been reported to cause $50 \%$ mortality in children [5]. Dengue is an arborviral infection transmitted by mosquito Aedes and unlike other viral hepatitis, the AST level tends to be higher than ALT due to damage of myocytes during dengue infection and peak at day 7 to 8 of illness [6]. In Malaysia, the highest AST level before liver dialysis was subjected was $>1000 \mathrm{U} / \mathrm{L}$, [7] but as for this patient the level was $9 \mathrm{x}$ higher $(9130 \mathrm{U} / \mathrm{L})$ of which grade 3-4 hepatic encephalopathy is actually a criteria for liver transplant. 
Table 1. Clinical Practice Guidelines, Management of Dengue Infection in Adults 3rd edition, 2015 [1].

\begin{tabular}{|c|c|c|c|c|c|c|}
\hline Day of Illness & $\begin{array}{c}\text { D2 } \\
\text { NAC }\end{array}$ & $\begin{array}{c}\text { D3 } \\
\text { SVD in ICU A/S } \\
0 / 0 / T\end{array}$ & $\begin{array}{c}\text { D5 } \\
\text { CPAP, CCRT \& } \\
\text { Thiamine }\end{array}$ & $\begin{array}{c}\text { D6 } \\
\text { Intubated, } \\
\text { Digoxin \& Ist } \\
\text { MARS started }\end{array}$ & $\begin{array}{c}\text { D8 } \\
\text { AF Resolved } \\
\text { 3rd MARS } \\
\text { completed }\end{array}$ & $\begin{array}{c}\text { D16 } \\
\text { Extubated }\end{array}$ \\
\hline TWC & 7.4 & 12.5 & 37.3 & 45.9 & 13.6 & 4.7 \\
\hline $\mathrm{Hb}$ & 11.8 & 14.1 & 13.6 & 11.3 & 8.1 & 9.6 \\
\hline Platelet & 220 & 61 & 51 & 93 & 216 & 300 \\
\hline AST & 413 & 1105 & 5671 & 9130 & 5498 & 200 \\
\hline ALT & 117 & 476 & 2533 & 4555 & 1986 & 44 \\
\hline $\mathrm{LDH}$ & 495 & 722 & 5577 & 8165 & 3843 & 500 \\
\hline Bilirubin & 46 & 85.4 & 219 & 231 & 116 & 86 \\
\hline Ammonia & - & 265 & 301 & 997 & 165 & 79 \\
\hline $\mathrm{pH}$ & 7.44 & 7.3 & 7.36 & 7.32 & 7.45 & 7.43 \\
\hline Base excess & -8.6 & -15.8 & -12.6 & -17.2 & -4.2 & 3.4 \\
\hline Lactate & 2.7 & 5.5 & 13.2 & 13.8 & 7.9 & 0.9 \\
\hline Urea & 1.9 & 2.9 & 5 & 6.7 & 6.0 & 3.6 \\
\hline Creatinine & 51.4 & 59.7 & 85.6 & 89.1 & 70.5 & 42.6 \\
\hline APTT & 48.1 & 51.2 & 47.4 & 40.7 & 38.4 & 39.3 \\
\hline INR & 1.19 & 1.26 & 1.61 & 2.27 & 2.01 & 0.89 \\
\hline
\end{tabular}

OLINIOAL OOURSE OF DHF

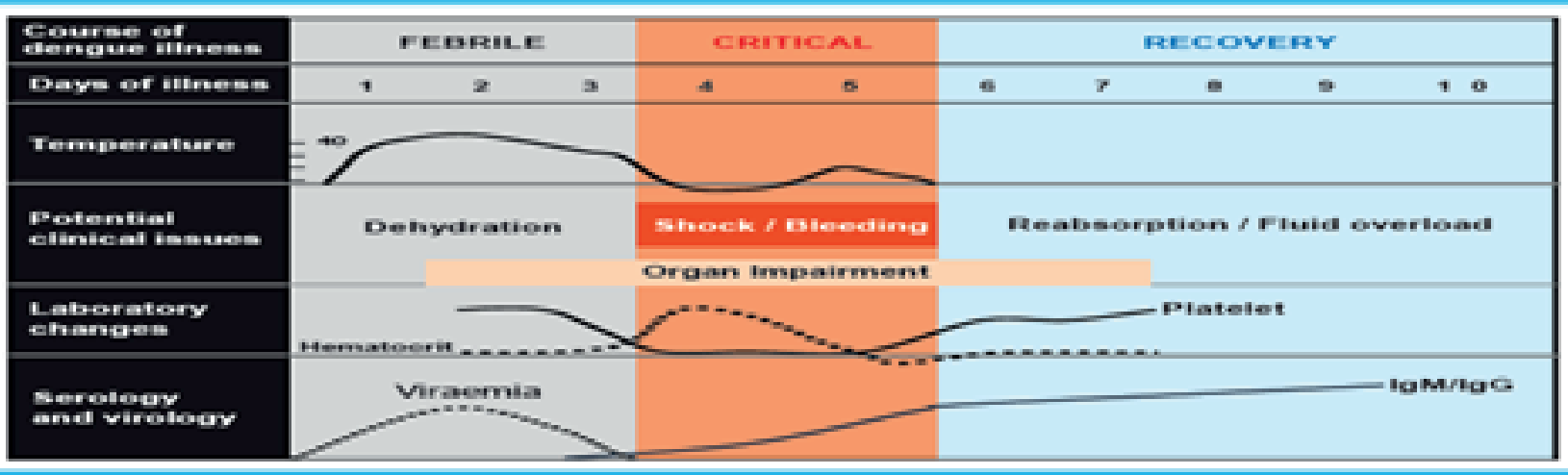

Note; Onest of defervesoence vevally oocure between day 3 to day 5 of illnese

Figure 1. Clinical course of DHF.

\section{Conclusion}

MARS function based on concept of albumin dialysis, removing water soluble and albumin bound toxin [8] and this case revealed that MARS is safe and efficient as lifesaving treatment for fulminant hepatic failure.

\section{References}

1. Clinical Practice Guidelines. Management of Dengue Infection in Adults. (3rd edn), 2015.

2. Sahai S, Kiran R. Acute Liver Failure in Pregnancy: Causative and Prognostic Factors. Saudi J Gastroenterol. 2015; 21: 30-34.

3. Gotthardt D, Riediger C, Weiss KH, et al. Fulminant Hepatic failure: etiology and indications for liver transplantation. Nephrol Dial Transplant. 2007; 22: Sviii5-Sviii8.
4. de Naeyer S, Ysebaert D, van Utterbeeck M, et al. Acute fatty liver of pregnancy and MARS therapy: case report. J Matern Fetal Neonatal Med. 2008; 21: 587-589.

5. Shah I. Dengue and liver disease. Scand J Infectious Dis. 2008; 40: 993-994.

6. Kularatne S, Imbulpitiya IVB, Abeysekera RA, et al. Extensive haemorrhagic necrosis of liver is an unpredictable fatal complication in dengue infection: a postmortem study. BMC Infect Dis. 2014; 14: 141.

7. Tan SS, Bujang MA. The clinical features and outcomes of a liver failure: a case series. Braz J Infect Dis. 2013; 17: 164-169.

8. Faybiik P, Hetz H, Krenn CG, et al. Liver support in fulminant liver failure after haemorrhagic shock. Wien Klin Wochenschr. 2003; 115: 595-598. 